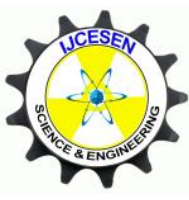

Copyright (C) IJCESEN
International Journal of Computational and

Experimental $\boldsymbol{S}$ cience and Engineering

(IJCESEN)

Vol. 4-No.3 (2018) pp. 25-29

http://dergipark.gov.tr/ijcesen

Research Article

\title{
Study on Performance of Progressing Cavity Pumps (PCPs) in Different Fit Modes
}

\author{
Lei ZHENG ${ }^{*}$, Xiaodong WU', Ruidong $\mathrm{ZHAO}^{2}$, Huachang $\mathrm{LI}^{3}$ and Mengyun $\mathrm{LIU}^{1}$ \\ ${ }^{1}$ MOE Key Laboratory of Petroleum Engineering, China University of Petroleum (Beijing), 102249, Beijing-China \\ ${ }^{2}$ Research Institute of Petroleum Exploration \& Development, CNPC, 100083, Beijing-China \\ ${ }^{3}$ Sinopec International Petroleum Service Corporation, 100020, Beijing-China \\ * Corresponding Author : sydxzhenglei@163.com \\ ORCID: 0000-0003-4774-2071
}

\section{Article Info:}

DOI: $10.22399 /$ ijcesen.474462

Received : 24 October 2018

Accepted : 7 November 2018

\section{$\underline{\text { Keywords }}$}

Progressing cavity pump

Fit parameter

Volumetric characteristics

Power consumption

Work efficiency

\begin{abstract}
$\underline{\text { Abstract: }}$
The performance of progressing cavity pumps (PCPs) is significantly different in different fit modes between the stators and rotors, such as interference fit for conventional PCPs with rubber stators and clearance fit for novel all metal PCPs. In order to study the influence of fit modes on PCP performance, a novel concept of the fit parameter is introduced to quantitatively describe the fit condition. Based on working principles of PCPs, comprehensive studies are carried out on the pump performance in different fit modes, including the volumetric characteristics, power consumption and work efficiency. The results show that the theoretical pump rate slightly decreases with the increase of the fit parameter. Though there is obvious friction inside the pump and the interference has a great impact on the power consumption, the PCP in interference fit is able to achieve high volumetric efficiency $(>80 \%)$. Though there is inevitable leakage and the clearance has a significant influence on the flow rate, the PCP in clearance fit can reach high mechanical efficiency $(>90 \%)$. The novel all metal PCP in clearance fit has enormous potential for development owing to its good overall performance.
\end{abstract}

\section{Introduction}

The progressing cavity pump (PCP) has been widely used as an effective artificial lift method in the oil field development, which shows significant advantages, such as low cost, easy installation, high efficiency and adaptation to complex working conditions. But there are still some deficiencies in resisting wear and temperature for conventional PCP, which operates with the rubber stator and metallic rotor in interference fit. Now a new type of all metal PCP in clearance fit has been developed to overcome these limitations [1], in which both the stator and rotor are made of metallic materials. Therefore, the fit modes of PCPs become more diversified and not limited to the traditional interference fit. Many studies have been conducted on the performance of conventional PCPs in interference fit and all metal PCP in clearance fit respectively [2-5], indicating that results are significantly different. However, there is still a lack of studies on the PCP performance based on the fit condition between the stator and rotor, namely considering different fit modes comprehensively. In this paper, a fit parameter is introduced to study the PCP performance in consideration of fit modes. The conventional PCP and all metal PCP are taken as typical examples to analyze the relationship between the performance and fit parameter. This study can provide a theoretical basis for the PCP design and the choice of PCP types in the oil field application.

\section{PCPs in Different Fit Modes}

\subsection{Basic Structure}

As shown in Figure 1, the fit modes of PCP mainly depend on the relative size of its stator and rotor, which can be defined by a new parameter, given as: 


$$
\delta=\frac{d_{\mathrm{r}}-d_{\mathrm{s}}}{2}
$$

Where $\delta$ is the fit parameter, $\mathrm{m} ; d_{\mathrm{r}}$ is the rotor diameter, $\mathrm{m} ; d_{\mathrm{s}}$ is the stator diameter, $\mathrm{m}$.

Therefore, the case of $\delta=0$ represents the exact fit (Figure 1a), which rarely exists in actual situations; the case of $\delta>0$ represents the interference fit (Figure $1 \mathrm{~b}$ ); the case of $\delta<0$ represents the clearance fit (Figure 1c). It is notable that the red section in each figure is the flow cross-sectional area during PCP operation of pumping fluid.

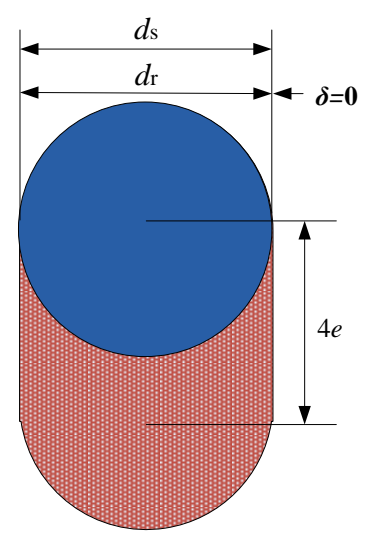

(a) Exact fit

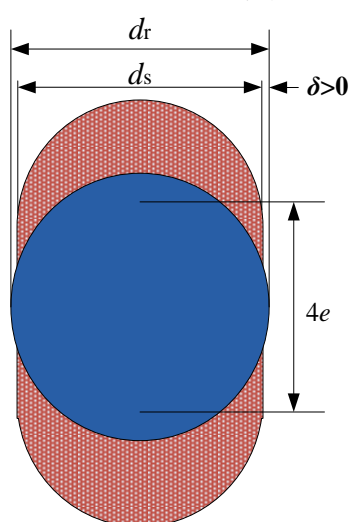

(b) Interference fit

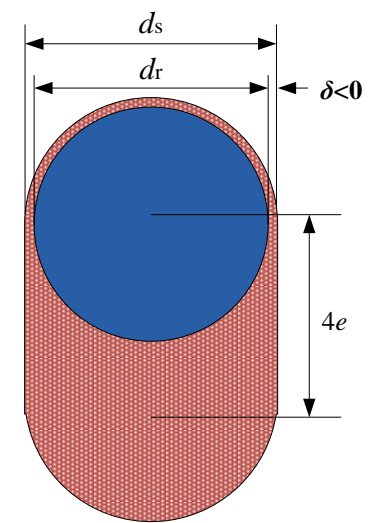

(c) Clearance fit
Figure 1. Different fit modes between stator and rotor

Considering the influence of the fit parameter on the flow rate inside the pump, the flow crosssectional area in different fit modes can be calculated as:

$A=\left\{\begin{array}{l}4 e d_{\mathrm{r}}, \delta=0 \\ 2\left[\frac{d_{\mathrm{r}}^{2}}{4} \arcsin \left(\frac{2 \sqrt{\delta d_{\mathrm{r}}-\delta^{2}}}{d_{\mathrm{r}}}\right)-\sqrt{\delta d_{\mathrm{r}}-\delta^{2}} \cdot\left(\frac{d_{\mathrm{r}}}{2}-\delta\right)\right] \\ +4 e d_{\mathrm{r}}-8 e \delta-\pi\left(\delta d_{\mathrm{r}}-\delta^{2}\right), \delta>0 \\ 4 e d_{\mathrm{r}}-8 e \delta-\pi\left(\delta d_{\mathrm{r}}-\delta^{2}\right), \delta<0\end{array}\right.$

Where $e$ is the pump eccentricity, m.

Then the theoretical pump rate can be calculated as:

$$
Q_{\mathrm{t}}=1440 n A T
$$

Where $n$ is the rotational speed, $\mathrm{r} / \mathrm{min} ; T$ is the stator pitch, $\mathrm{m}$.

\subsection{Working Principles}

The PCP body is divided into several cavities by the mutual meshing movements of the stator and rotor during the pump operation. Each cavity moves spirally from the inlet to the outlet along the pump, realizing the process of fluid pressurizing and lifting. For the PCP in interference fit, these cavities can be well sealed and little leakage occurs at relatively low lifting pressure, in which the flow rate is approximately equal to the theoretical pump rate. But when the lifting pressure becomes higher than the pressure-bearing limit corresponding to the interference, the rubber stator can be penetrated and the leakage flow occurs [6]. For the PCP in clearance fit, cavities along the pump connect with each other and fluid leakage exists objectively during the pump operation. However, the lifting capacity can be ensured by the viscous resistance of the fluid, which has a certain sealing effect on the leakage flow in the clearance between the stator and rotor.

\section{Performance Analysis}

\subsection{Volumetric Characteristics}

Based on the working principles mentioned above, the leakage characteristics of PCPs are closely related with the fit modes, which can influence the volumetric characteristics significantly [7]. The actual flow rate can be obtained by subtracting the leakage from the theoretical pump rate, given as:

$$
Q=Q_{\mathrm{t}}-q
$$

Where $Q$ is the actual flow rate, $\mathrm{m}^{3} / \mathrm{d} ; q$ is the leakage, $\mathrm{m}^{3} / \mathrm{d}$.

For PCPs in interference fit, the pressure-bearing limit depends on the pump structure and working conditions, which can be obtain by experimental analysis [3], given as:

$$
\Delta p_{\mathrm{k}}=k n^{0.25} t^{0.21} \mu^{0.08} \delta Z, \delta>0
$$

Where $k$ is a constant related with the stator property, which is 0.12 for the stator made of acrylonitrilebutadiene Rubber (NBR)[3]; $t$ is the operating temperature, ${ }^{\circ} \mathrm{C} ; \mu$ is the fluid viscosity, $\mathrm{mPa} \cdot \mathrm{s} ; Z$ is the number of pump stages.

Then the volumetric efficiency of PCPs in interference fit can be calculated by the following empirical formula as [3]:

$$
\eta_{\mathrm{v}}=\left\{\begin{array}{l}
1-\frac{\alpha}{\Delta P_{\mathrm{k}}} \Delta p, \Delta p \leq \Delta p_{\mathrm{k}} \\
1-\alpha-0.015\left(\Delta p-\Delta p_{\mathrm{k}}\right)^{\beta}, \Delta p>\Delta p_{\mathrm{k}}
\end{array}, \delta>0\right.
$$

Where $\Delta p$ is the total lifting pressure, $\mathrm{MPa} ; \alpha$ is a constant determined by the stator, which is 0.05 for 
the NBR stator; $\beta$ is a constant related with pump geometrical parameters.

For PCPs in clearance fit, the pressure increases approximately linearly from the inlet cavity to the outlet cavity during the pump operation [8]. According to the clearance flow theory [9], the fluid leakage caused by differential pressure in the clearance can be expressed as:

$$
q=k \frac{(-\delta)^{3} \Delta p}{12 \mu Z}, \delta<0
$$

Where $q$ is the leakage, $\mathrm{m}^{3} / \mathrm{d} ; k$ is a constant related with the clearance structure, which is equal to the ratio of the clearance width to the clearance length; $\Delta p / Z$ is equal to the single-stage pressure difference, MPa.

Then the volumetric efficiency of PCPs in clearance fit can be calculated as:

$$
\begin{aligned}
& \eta_{\mathrm{v}}=\frac{Q_{\mathrm{t}}-q}{Q_{\mathrm{t}}} \\
& =1-\frac{k(-\delta)^{3}}{17280 \mu n T Z\left[4 e d_{\mathrm{r}}-8 e \delta-\pi\left(\delta d_{\mathrm{r}}-\delta^{2}\right)\right]} \Delta p, \delta<0
\end{aligned}
$$

\subsection{Power Consumption}

During working of PCPs in different fit modes, the total power consumption can be generally reflected by the shaft power, which mainly consists of the theoretical hydraulic power and the frictional loss power. The former power is linear to the lifting pressure, while the latter power is closely related with the frictional condition between the stator and rotor inside the pump [10]. Therefore, the total power consumption can be given as:

$$
\begin{gathered}
P=P_{\mathrm{u}, \mathrm{h}}+P_{\mathrm{f}}=\left(P_{\mathrm{u}}+P_{\mathrm{s}}\right)+P_{\mathrm{f}} \\
P_{\mathrm{u}}=\frac{Q \cdot \Delta p}{86.4} \\
P_{\mathrm{s}}=\frac{q \cdot \Delta p}{86.4}
\end{gathered}
$$

Where $P$ is the total power consumption, $\mathrm{kW} ; P_{\mathrm{u}, \mathrm{th}}$ is the theoretical hydraulic power, $\mathrm{kW} ; P_{\mathrm{u}}$ and $P_{\mathrm{s}}$ are respectively the active power and the leakage loss power, $\mathrm{kW} ; P_{\mathrm{f}}$ is the frictional loss power, $\mathrm{kW}$.

The hydraulic power (such as $P_{\mathrm{u}}$ and $P_{\mathrm{s}}$ ) is corresponding to the volumetric characteristics mentioned above. The frictional loss power is comprehensively influenced by the fit modes and other operating parameters. Among them, the fit parameter can directly determine the frictional force between the stator and rotor. Due to the computational complexity of the frictional loss power $[11,12]$, it can be obtained by the regression analysis of experimental data of PCPs in different fit modes [5, 13].

\subsection{Work Efficiency}

The total efficiency of PCPs in different fit modes is the ratio of the active power to the shaft power, which also equals to the product of the volumetric efficiency and the mechanical efficiency [14], given as:

$$
\begin{gathered}
\eta=\frac{P_{\mathrm{u}}}{P}=\eta_{\mathrm{v}} \cdot \eta_{\mathrm{m}} \\
\eta_{\mathrm{m}}=1-\frac{P_{\mathrm{f}}}{P}
\end{gathered}
$$

Where $\eta_{\mathrm{m}}$ is the mechanical efficiency.

\section{Results and discussion}

Based on the mathematical analyses above, a simulator can be developed to model the PCP performance in different fit modes using Visual Basic for Application (VBA). The conventional PCP with NBR stator and all metal PCP are respectively taken as examples to simulate the pump performance and analyze the relationship between the fit parameter and pump performance. The basic geometrical parameters and lifting parameters of two PCPs are designed to be the same except the fit parameter, as shown in Table1.

Table 1. Basic parameters of PCPs

\begin{tabular}{|l|l|}
\hline Variable & Value \\
\hline Stage number & 20 \\
\hline Rotor diameter, $\mathrm{mm}$ & 50 \\
\hline Stator pitch, $\mathrm{mm}$ & 160 \\
\hline Eccentricity, $\mathrm{mm}$ & 5 \\
\hline Fluid viscosity, $\mathrm{mPa} \cdot \mathrm{s}$ & 40 \\
\hline Temperature, ${ }^{\circ} \mathrm{C}$ & 55 \\
\hline Lifting pressure, $\mathrm{MPa}$ & 8 \\
\hline Rotational speed, $\mathrm{r} / \mathrm{min}$ & 120 \\
\hline
\end{tabular}

The fit condition between the stator and rotor can be quantitatively described by the fit parameter $\delta$. The positive range $(\delta>0)$ corresponds to the interference fit for the conventional PCP, in which the bigger the fit parameter is, the larger the interference will be. The negative range $(\delta<0)$ corresponds to the clearance fit for all mental PCP, in which the bigger the fit parameter is, the smaller the clearance will be. As the exact fit mode rarely exists, the relationship curve of the fit parameter and the pump performance is not continuous at the point of $\delta=0$.

The volumetric characteristics based on the fit condition between the stator and rotor are simulated, as shown in Figure 2. Results show that, with the increase of the fit parameter, both the theoretical pump rate and fluid leakage decrease in different fit modes. For PCPs in interference fit $(\delta>0)$, the extreme interference value is $0.323 \mathrm{~mm}$ corresponding to the pressure-bearing limit, which 
means the pump cavities are penetrated and the leakage flow happens when $\delta$ ranges from 0 to $0.323 \mathrm{~mm}$. When $\delta$ is above $0.323 \mathrm{~mm}$, the pump can operate normally. It is the reason why the actual flow rate firstly increases and then decreases with the increase of the fit parameter. For PCPs in clearance fit $(\delta<0)$, due to the leakage flow in the clearance, the fit parameter has a significant influence on the flow rate. When $\delta$ increases from $-0.3 \mathrm{~mm}$ to $0.05 \mathrm{~mm}$, the fluid leakage decreases rapidly from $17.52 \mathrm{~m}^{3} / \mathrm{d}$ to $5.64 \mathrm{~m}^{3} / \mathrm{d}$, and the corresponding actual rate increases rapidly by $89.3 \%$.

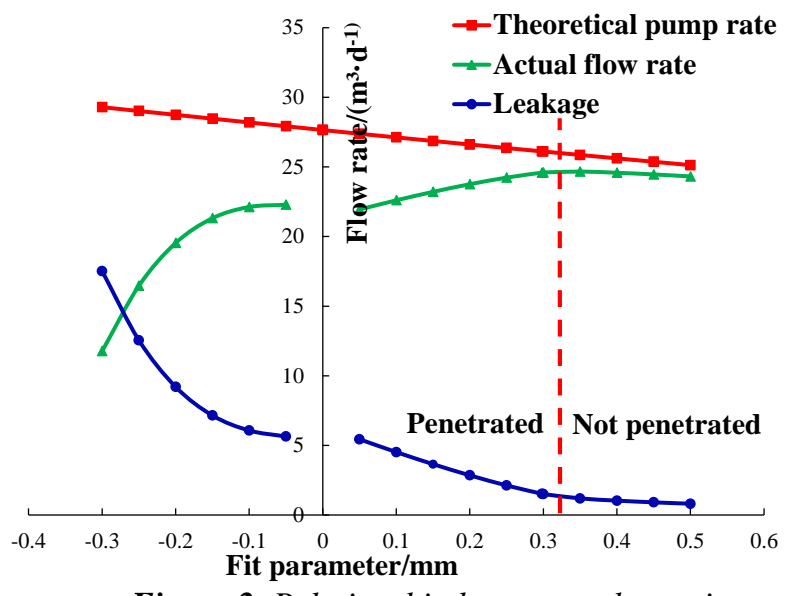

Figure 2. Relationship between volumetric characteristics and fit parameter

The power consumption based on the fit condition between the stator and rotor is simulated, as shown in Figure 3. The total power consumption increases with the increase of the fit parameter, and it needs to be noted that the total power consumption in interference fit $(\delta>0)$ is much larger than that in clearance fit $(\delta<0)$. It is mainly determined by the fact that the friction situation between the stator and rotor is positively correlated with the interference value. For the cases of both two fit modes, with the increase of the fit parameter, the active power increases and the leakage loss power decreases. Besides, results show that the influence of the fit parameter on the hydraulic power $\left(P_{\mathrm{u}}\right.$ and $\left.P_{\mathrm{s}}\right)$ in clearance fit is obviously greater than that in interference fit. The work efficiency based on the fit condition between the stator and rotor is simulated, as shown in Figure 4. For PCPs in clearance fit $(\delta<0)$, with the increase of the fit parameter, the volumetric efficiency increases rapidly, while the mechanical efficiency decreases slowly and keeps at a relatively high level. As a result, the total efficiency increases rapidly at beginning and then the increment becomes gentle, indicating more seriously affected by the volumetric performance. According to this rule, an optimum clearance can be designed for the PCP in clearance fit under certain

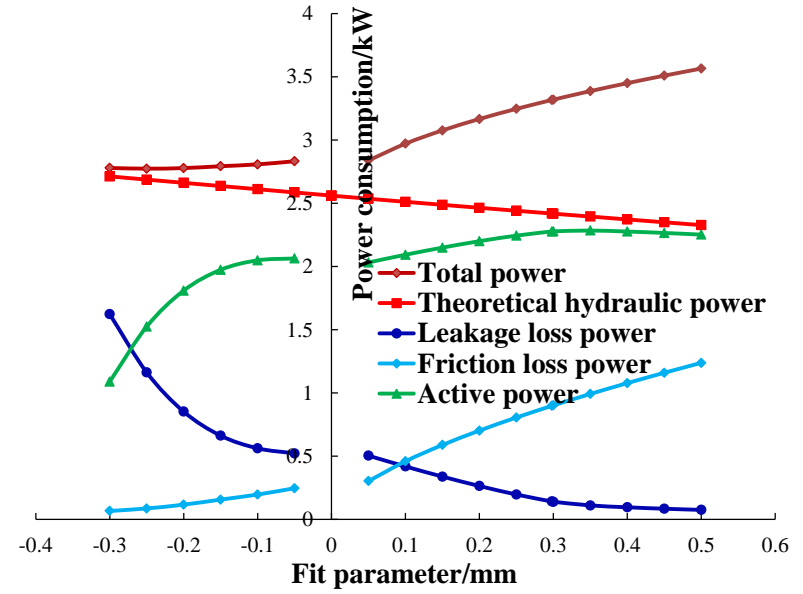

Figure 3. Relationship between power consumption and fit parameter

operating conditions. For PCPs in interference fit $(\delta>0)$, it can realize much higher and more stable volumetric efficiency, especially under the condition where the rubber stator is not penetrated. Combining the negative effect of the fit parameter on the mechanical efficiency, the total pump efficiency presents a decline trend. On the whole, results illustrate that PCPs in interference fit can achieve the volume efficiency above $80 \%$ (even above $90 \%$ during normal operating); PCPs in clearance fit can achieve the mechanical efficiency above $80 \%$, and can realize higher total efficiency with an appropriate design for the fit clearance. Therefore, the novel all metal PCP also has great potential to be developed, which can be regarded as a good alternative pump for pumping fluid.

\section{Conclusions}

The fit mode between the stator and rotor has a significant influence on the PCP performance, including the volumetric characteristics, power consumption and work efficiency. The fit parameter can be used to describe the fit condition quantitatively and analyze the PCP performance in different fit modes. The relationship between the PCP performance and the fit parameter has been simulated comprehensively in consideration of various fit conditions. The results show that, as the fit parameter varies, the volumetric efficiency and mechanical efficiency of the PCP in a specific fit mode change in opposite trends. By contrastive analyses, the conventional PCP in interference fit is able to achieve better volumetric characteristic, while the novel all metal PCP in clearance fit can ensure greater mechanical characteristic. It indicates the PCP in clearance fit is also feasible to pump fluid, which can be regarded as an additional facility to the conventional PCPs. 


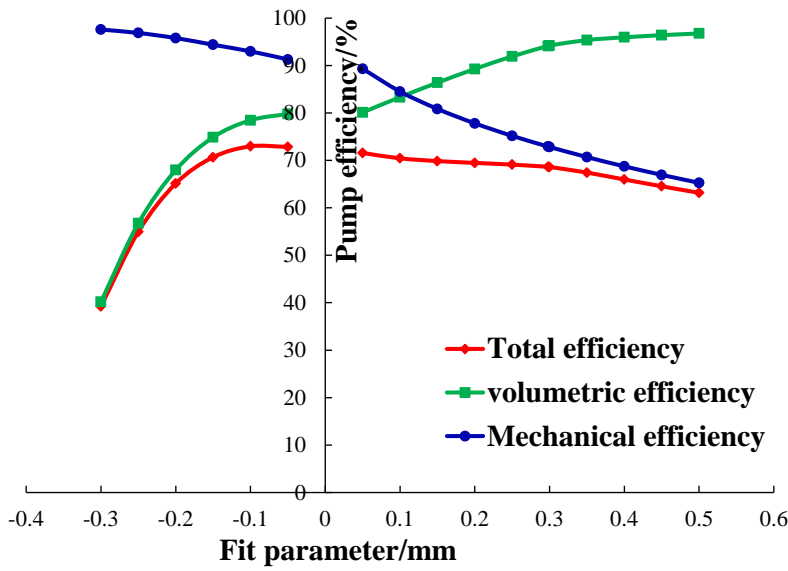

Figure 4. Relationship between work efficiency and fit parameter

Remarkably, during the real production of the artificial lift, the novel all metal PCP is more preferable to be used considering its long operating life and high temperature resistance.

\section{Acknowledgement}

Authors thanks to the National Science and Technology Major Project (NSTMP) Program (grant number: 2017ZX05072006-002) and the National Science and Technology Major Project (NSTMP) Program (grant number: 2017ZX05009-003) in China.

This paper was presented in " 4 rd International Conference on Computational and Experimental Science and Engineering (ICCESEN-2017)"

\section{References}

[1] J.L. Beauquin, F.O. Ndinemenu, G. Chalier, L. Lemay, L. Seince, A. Damnjanovic. World's first metal PCP SAGD field test shows promising artificial-lift technology for heavy-oil hot production: Joslyn field case. SPE annual technical conference and exhibition, Society of Petroleum Engineers, Anaheim 2007, ID: SPE-110479-MS.

[2] Y. Wang, X. Du. Effect of rotate speed test and temperature for hydraulic characteristic of PCP. Oil Field Equipment, 4, 40 (2011).

[3] J. Wei, W. Wu, Y. Zeng, J. Guo, F. Lin. Numerical simulation and application of performance characteristics of progressive cavity pump. Oil Drilling \& Production Technology, 4, 28 (2006).

[4] J. Gamboa, A. Olivet, S. Espin. New approach for modeling progressive cavity pumps performance. SPE annual technical conference and exhibition, Society of Petroleum Engineers, Denver 2003, ID: SPE-84137-MS.

[5] J. L. Beauquin, C. Boireau, L. Lemay, L. Seince. Development status of a metal progressing cavity pump for heavy oil and hot production wells. SPE international thermal operations and heavy oil symposium, Society of Petroleum Engineers, Calgary 2005, ID: SPE- 97796-MS.
[6] F. Zegrar, S. Boucetta, B. Othmani. High pressure behavior of elastic and mechanical properties of $\mathrm{NiGa}$ intermetallic compound. International Conference on Computational and Experimental Science and Engineering (ICCESEN 2015), Antalya 2015. DOI: 10.12693/APhysPolA.130.471.

[7] C. Zhou, X. Wu, H. Li, Z. Ren, Y. Xin. Influence of in-situ stress distribution on selection of fracturing fluid backflow technology. International Conference on Computational and Experimental Science and Engineering (ICCESEN 2015), Antalya 2015. DOI: 10.12693/APhysPolA.130.347.

[8] S.F. Andrade, J. Valrio, M. Carvalho. Asymptotic model of the $3 \mathrm{D}$ flow in a progressing-cavity pump. SPE Journal, 2, 16(2011), ID: SPE-142294-PA.

[9] G. Vetter, W. Wirth, H. Korner, S. Pregler. Multiphase pumping with twin-screw pumps-understand and model hydrodynamics and hydroabrasive wear. Proceedings of the 17 th international pump users symposium, Houston 2000.

[10] R. Kiliç. Determination of imbalance problem in electric motor and centrifugal pump by vibration analysis. International Conference on Computational and Experimental Science and Engineering (ICCESEN 2015), Antalya 2015. DOI: 10.12693/APhysPolA.130.487.

[11] N. Ozsoy, M. Ozsoy, A. Mimaroglu. Influence of parameters on tribological behaviour of E-Glass fiber reinforced epoxy composites. International Conference on Computational and Experimental Science and Engineering (ICCESEN 2015), Antalya 2015. DOI: 10.12693/APhysPolA.128.B-55.

[12] O. Boubaker, B. Said. Investigation on mechanical properties of $\mathrm{Mn}_{3} \mathrm{Sb}$ intermetallic compound. International Conference on Computational and Experimental Science and Engineering (ICCESEN 2015), Antalya 2015.2 DOI: 10.12693/APhysPolA.130.33.

[13] J. Wei, G Shi. Rod string torque calculation of progressive cavity pump. China Petroleum Machinery, 9, 23 (1995).

[14] Y. Lv, X. Wu, Y. Li, Q. Wang. Progressing cavity pump well system efficiency analysis model and its application. Oil Drilling \& Production Technology, 1, 28 (2006). 